\title{
Multi-criteria Assessment of Innovative Technology in the Beef Industry
}

\author{
Hayley Moreland \\ The University of Queensland, St. Lucia. Brisbane. Australia \\ $\&$ \\ CRC Beef Genetic Technologies, St. Lucia. Brisbane. Australia \\ E-mail: h.moreland@uq.edu.au
}

Paul Hyland (Corresponding author)

Queensland University of Technology, GPO Box 2434, Brisbane. 4001. Australia

Tel: 61-731-382-938 Fax:61-731-381-313 E-mail: paul.hyland@qut.edu.au

\begin{abstract}
In Australia rural research and development corporations and companies expended over \$AUS500 million on agricultural research and development. A substantial proportion of this is invested in R\&D in the beef industry. The Australian beef industry exports almost \$AUS5billionof product annually and invest heavily in new product development to improve the beef quality and improve production efficiency. Review points are critical for effective new product development, yet many research and development bodies, particularly publicly funded ones, appear to ignore the importance of assessing products prior to their release. Significant sums of money are invested in developing technological innovations that have low levels and rates of adoption. The adoption rates could be improved if the developers were more focused on technology uptake and less focused on proving their technologies can be applied in practice. Several approaches have been put forward in an effort to improve rates of adoption into operational settings. This paper presents a study of key technological innovations in the Australian beef industry to assess the use of multiple criteria in evaluating the potential uptake of new technologies. Findings indicate that using multiple criteria to evaluate innovations before commercializing a technology enables researchers to better understand the issues that may inhibit adoption
\end{abstract}

Keywords: Innovation fit, Beef industry, Improved adoption

\section{Introduction}

Increasingly, governments are seeking ways to gain better returns from their investments in publicly funded research and development (R\&D). In Australia, one policy response has been to fund collaborative research centers that involve research bodies such as universities, government entities, and industry. The Cooperative Research Centers (CRCs) are under increasing pressures to commercialize their research into technological innovations that can be adopted by the industry for commercial benefit or in some cases, for public good. According to Whan et al. (2006), the CRC program established in 1990 covers a wide variety of industry sectors. Of existing CRCs established the beef industry CRC has been particularly successful and the current Beef CRC for Beef Genetic Technologies was established in 2005. Based on this approach, a study into innovation adoption was funded, and this research reports on some of the findings from one innovation adoption study. Whan, Bortolussi, \& Backus (2006) argue, that genetic technologies present the industry with more complex issues than in the past, and ongoing investment in understanding technology adoption is required to maintain the industry's ability to understand these complex technologies and to apply them in practice.

According to the Australian Bureau of Agricultural Research and Economics (ABARE, 2006), effective dissemination and adoption of innovations by industry are important in maintaining productivity in the Australian agriculture. Government and industry bodies play a critical role in promoting the adoption of technological innovations and new products that have the greatest potential benefits. This research focuses on technological innovations that are the result of the research and development pipeline.

As Slater and Mohr (2006) point out, technological innovations are products that over time may eventually displace existing products in most cases because they have a relative advantage over existing products. However, to displace existing products, they need to enable the end-user's business to achieve improvements or to gain differentiation, (Damanpour \& Wischnevsky, 2006; Hausman, 2005; Klerkx \& Leeuwis, 2007). 
Schmidt, Sarangee, \& Montoya (2009) highlighted the high failure rate and high risk nature of new product development in commercial entities and they argued that one way to manage risk is to introduce review points during the development process. If, as Schmidt et al. (2009) argue, review points are crucial for effective new product development, then government-funded $\mathrm{R} \& \mathrm{D}$ organizations such as CRCs seeking to commercialize technological innovations would benefit from reviewing their products at different stages of development. In this research it is argued that the most effective way to evaluate new technologies is to use a multi-criteria frame that considers the needs and practices of the end users to ensure an 'innovation fit' between the end users' needs and environment. 'Innovation fit' is the level of alignment between perceived innovation characteristics and the requirements of the end users. So innovations that are adopted will be those that meet most of the end user's requirements. So are experts able to evaluate if R\&D projects alignment with end users needs? The objectives of this research are: (i) to demonstrate how 'innovation fit 'of technological innovations can be assessed using multiple criteria, and (ii) to demonstrate how a review of innovation characteristics can identify potential issues affecting the adoption of technological innovations in agriculture.

\subsection{Innovation adoption}

A number of bodies conduct research focused on increasing productivity and the sustainable competitive advantage of Australian agriculture. While universities, State Departments of Primary Industries (DPI), the Commonwealth Scientific and Industrial Research Organisation (CSIRO), and private companies are involved in beef industry research, the public sector is the foremost provider of $R \& D$ funding to Australian agriculture, providing more than half of the total investment (Mullen \& Crean, 2006). Research focused on achieving a sustainable competitive advantage over international competition is a priority for the Australian beef industry, as is increasing the marketing of the clean and green reputation, product differentiation, and continual innovation to keep quality high and prices competitive (Meat and Livestock Australia, 2008).

The adoption of innovation is not an immediate event; it is a multi-stage decision-making process (Wolfe, 1994). Rogers (1983) observed and categorized the innovation-adoption process and his model has been validated across a variety of disciplines (e.g. internet, electronic commerce and community studies) and is extensively used in the agricultural sector (Gregor \& Jones, 1999). The stages in this process have been redefined into two identifiable stages; initiation and implementation (Bouwman, Van den Hoof, Van de Wijngaert, \& Van Dijk, 2005; Gopalakrishnan \& Damanpour, 1997).

The initiation stage consists of three sub-stages; awareness, evaluation, and decision. During this stage of the process, a potential user becomes aware of an innovation and decides whether to trial it based on available information. An awareness of an innovation is instigated either by the potential user, an intermediary, or the innovation provider (Rogers, 2003; Wolfe, 1994). Upon trial, the innovation is evaluated by the end user. The decision to adopt an innovation is the end of the initiation stage and the start of the implementation stage (Gopalakrishnan \&Damanpour, 1997).During implementation the user incorporates the innovation into their day to day operations. The innovation is trialed on a small scale and evaluated as to its fit with current practices (Gopalakrishnan \& Damanpour, 1997). If the trial of the innovation is successful, it is assimilated into the organization, and this is the final stage of the adoption process (Gopalakrishnan \& Damanpour, 1997). To overcome shortcomings, the dissemination model was modified to what is known as the knowledge-utilization model which is an active approach to diffusion of innovation (Devine, James, \& Adams, 1987). The knowledge-utilization model encourages the end-user to identify and communicate problems they have encountered in their operations to help decide the direction of research and development projects undertaken by researchers. The knowledge-utilization model has been adopted by the Cooperative Research Centres (CRCs) system in Australia which incorporates industry into the agenda-setting of the research and development programs (Department of Education Science and Training, 2005). However simply incorporating industry into the agenda setting is only the first step.

\section{Innovation Fit}

The significance of 'innovation fit' is revisited as technologies become more complex it is increasingly important that they are aligned with the needs and the environment of the end user. In agriculture, particularly in beef production genetic technologies are being developed in an effort to improve the quality of eating meat and the efficiency of the beef production system. With this increasing complexity adoption of an innovation by a business is reliant on successful evaluation and trial. Innovations are evaluated on characteristics that influence their adoption. There is a wide variety of characteristics studied, and many authors and areas of research define different sets of characteristics as influencing the innovation adoption process (Rogers, 1962; Tornatzky \& Klein, 1982). The five characteristics as described by Rogers (1962) are relative advantage, complexity, compatibility, 
trialability, and observability. These have emerged from agricultural-based research and are the basis of many innovation and communication studies in the agricultural context (Guerin \& Guerin, 1994; Pannell et al., 2006; Van den Ban \& Hawkins, 1996). As can be seen in Figure 1, 'innovation fit' is currently assessed by the end-user at the evaluation stage during initiation. However, it is possible to use it earlier in the process as a review mechanism, either to determine the fit with existing operations or to identify issues that need to be addressed before technological products are released to end-users. In Figure 1 we propose that innovation characteristics can be used by experts and others as criteria to assess what we term the 'innovation fit' of a developmental technology.

Relative advantage is the advantage the new innovation has over predecessors or the current practices being employed by the potential user (Rogers, 2003). Relative advantage is measured by a number of factors, including increased profitability, reduced costs of feed animals, lower risk of disease, and improved market access by supplying better quality beef (Rogers, 2003). Compatibility refers to the degree to which an innovation aligns with the values, current enterprise, and lifestyle of a potential user (Rogers, 2003). The focus of compatibility is on ensuring new practices such as mustering without using dogs to reduce stress in animal can be done effectively without increasing costs.

Complexity of an innovation refers to how physically complicated the innovation is or the degree of knowledge required to understand how to use it (Rogers, 2003; Taylor \& McAdam, 2004). So food supplements that increase weight gain or improve fertility have low complexity. Observability of an innovation is the extent to which the results such as improved weight gain and growth from using growth promoting hormones are easily seen by the potential user and by others (Rogers, 1962). Trialability of an innovation is the degree to which the innovation can by implemented and trialed on a small scale (Rogers, 2003). The implementation of an innovation is facilitated by potential users' being able to implement the innovation on a small scale such as trial a feeding supplements with a sample of cattle and testing its effect to trial it (Rogers \& Shoemaker, 1971).

\section{Methodology}

This research was exploratory and employed a qualitative approach. Data were primarily collected using face-to-face semi-structured interviews. Semi-structured interviews were selected as the most appropriate method of data collection because they offer an opportunity to obtain in-depth accounts of the phenomenon from the perspectives of those within the context (Lee, 1999). The reliance of contextual realities makes semi-structured interviews an appropriate method for an exploratory study (Guba \& Lincoln, 2005). The interview questions were related directly to the criteria (relative advantage, compatibility, complexity, trialability, observability) identified by Rogers (2003). To limit the number of innovations, respondents were asked to identify the key technological innovations that have been developed for the beef industry from 1992-2007, their characteristics, and the communication strategies employed to transfer them to the potential users, and an estimated acceptance of the technical innovations by beef producers.

Purposeful sampling (Patton, 2002) was used to identify the informants from this target population. In this study, respondents were experts in the field of beef industry research, development and communication from research and industry bodies and government extension officers actively involved with beef producers keen to introduce new technologies; in total 25 respondents were interviewed. Informants were interviewed and the interview was digitally recorded and transcribed. Respondents' anonymity was assured and they were accorded codes. Management of the data was facilitated by the use of QSR NVivo as a database. Once the list of innovations had been reduced to the three key technological innovations, they were analyzed in detail. This analysis was conducted by thematic analysis of the interviews.

\section{Results}

The innovations discussed are summarised Table 1 which shows how often they were identified in interview data. These 13 innovations identified by respondents were reduced to the key technological innovations for further analysis. In order to select the key technological innovations, a number of criteria were used to determine the significance of the innovations (Patton, 2002).

BREEDPAN, DNA Markers, and MSA were the three innovations that met all the criteria so these can be regarded as key technological innovations. These three innovations were identified by most of the respondents.

BREEDPLAN is a software program based on a quantitative model that uses individual animal, parent, and sibling information to estimate the genetic potential of a particular animal. BREEDPLAN software was first released in 1984 and has continued to be updated and improved (Graser, Tier, Johnston, \& Barwick, 2005). There is a range of traits that are measured and converted to Estimated Breeding Values (EBVs). These EBVs 
are then used to compare animals within a breed to select genetically superior animals for breeding. Traits that are being assessed are growth traits, carcass traits, and reproductive traits.

DNA markers are specific sequences of DNA that identify particular genes in an organism. In the beef industry, the commercialized markers show how many favorable copies (zero, one, or two) of the gene an animal has for a particular production trait. For example, cattle have a number of genes that influence meat tenderness. One such gene is the Calpain gene. If the animal has two copies of the favorable form of this gene, it has the genetic potential to produce more tender beef than an animal with one positive and one negative form of the gene. In turn, an animal with one copy of the positive form of the gene will have a better chance of producing tender beef than an animal with zero copies of the favorable form of the gene.

The first DNA marker test was commercialized by an Australian company in 2000 (Hocquette, Lehnert, Barendse, Cassar-Malek, \& Picard, 2007), allowing cattle producers to identify animals with the favorable genes by having hair, semen, blood, or tissue samples tested.

Meat Standards Australia (MSA) is a meat grading system released to industry in 1999 (Meat and Livestock Australia, 2008). MSA goes beyond traditional grading systems in that while the meat grading occurs on the dead body, the grade incorporates whole-of-supply chain effects to give a descriptive, quality-assured end-product (Thompson, 2002). MSA was developed to increase beef consumption in Australia by increasing the consistency and predictability of tenderness in Australian beef. The MSA grade is calculated using data from all stages of the meat production chain, including breed make up, sex, age, time in lair age, carcass hanging method, post mortem cooling speed, and cooking method (Thompson, 2002). The result is a grade of unsatisfactory, good everyday (three-star), better than everyday (four-star) or premium quality (five-star) for every muscle in the body.

The general characteristics used to determine the 'innovation fit' of each technology are summarized in Table 2 .

Relative advantage is the advantage the new innovation has over the current practices and technologies being employed by users. The respondents were able to articulate the relative advantage of all three key innovations. When asked about BREEDPLAN, respondents indicated that end-users found the technology was better than previous visual systems of assessing traits for breeding purposes. BREEDPLAN was considered by all respondents to have advantages over its predecessors for use as a selection tool.

"BREEDPLAN ... help(s) producers better select the right genetics to target a market" (E3).

The majority of respondents also reported that DNA markers had a relative advantage over previous methods of animal selection in terms of increased accuracy and speed of obtaining information.

"If you can link all that information with a molecular gene marker, or more likely a suite of molecular gene markers that are associated with the traits that you are selecting for, then that increases the precision or the confidence that the animal actually has the genetic make-up that you are looking for" (RU2).

The MSA meat grading program was considered to have a high level of relative advantage over the traditional meat grading system by all respondents who identified it as an important innovation. A typical response was:

"It (MSA) certainly has (advantages). Most of the pre-existing systems were based on very simple measurements, maybe just weight and fat depths, or visual appraisal and people knew they weren't adequate, they weren't sufficient, they weren't accurate, they weren't reliable" (RS2).

Complexity is how physically complicated the innovation is or the degree of knowledge required to understand how to use it. BREEDPLAN was seen as very complex for producers to understand:

"It's (the complexity) been probably one of the biggest limitations, because some producers want to get to the bottom of all of the technologies"(E6).

Informants were more critical of DNA markers, with respondents stating that DNA markers were complicated and hard to understand. When asked about the level of complexity of DNA markers, one extension officer replied:

"Extremely. It's just happening at a different level. It's confusing for me" (E4).

While the consensus was that the innovation is complex, there was some variation in how this complexity impacted the end-user. Some suggested that the science behind the product was sophisticated and complicated, but that it did not impact the users. One respondent thought cattle producers were still confused on how to use the product: 
"I think quite honestly it scares the hell out of a lot of producers. I mean, you get a couple of lab coats up in front of a group of people and talking some pretty high level science” (IB5).

The data indicated that informants had differing views of MSA in terms of complexity. The majority of respondents regarded MSA as having low levels of complexity. Respondents acknowledged that the science that informs the MSA grading system is complicated; however, there was no indication that this complexity concerned the end-user. The data indicate that the complexities of MSA are not being transferred to the beef producers. Further, the clear goal of increasing beef palatability makes users more accepting of any complexity that does exist:

Trialability is the extent to which an innovation can by implemented and trialed on a small scale. While theoretically BREEDPLAN can be trialed on a small group of animals within a herd, it is rarely trialed as the lag time and the low observability makes trialing impractical. As one extension officer explained,

"Not very easy at all, because it (the results of BREEDPLAN selection) is so slow. Two, three, four years down the track" (E4).

As with BREEDPLAN, DNA markers have been introduced to help breeders select cattle based on traits that are hard or impossible to measure directly on the live animal. This characteristic of the innovation makes trialing and direct observation of the changes resulting from DNA markers difficult to see.

There was no consensus in the trialability of MSA. Respondents acknowledged that a small number of cattle could be processed under MSA conditions, making trialing the effect of the MSA system relatively simple.

However, some respondents did not believe that measuring the impact of MSA was straightforward and therefore trialing MSA was not effective. The responses regarding the trialability of MSA were often grouped with the observability responses. Observability is the extent to which the results are easily seen by the potential user. Therefore, due to the mixed responses, MSA's observability was unclear.

BREEDPLAN was found to have low observability, and while the ability to assess traits that are not visible in the live animal is one of its advantages over predecessors, the low observability reduces the adoptability. This was also the case for DNA markers. The lag time between introduction and ability to see the results was another source of poor observability:

"If they (cattle producers) have an expectation that they are going to be able to see these big differences and recoup their money and make money out of it, then I think they've been given the wrong messages" (R1).

Most of the informants agreed that it is difficult for beef producers to observe the benefits of DNA markers, whether the benefits of DNA markers are viewed as being finacial pay-offs or improvement in cattle quality.

"In terms of gene markers, I just don't know whether we've got to the stage to show that they have tangible, economic benefits." (RS1).

Compatibility is the degree to which an innovation aligns with the values currently held in the enterprise, the lifestyle of a potential user, and how effectively the innovation can be implemented into the existing activities and practices without disrupting the system or contradicting the values of the users. Most respondents held the view that BREEDPLAN was difficult to integrate and therefore has low compatibility.

While the innovation can be introduced easily, it is difficult to integrate fully into most enterprises because producers are not clear on how to use it to improve their herd.

"They (farmers) don't understand it. Because there are apparent contradictions. See BREEDPLAN is one of those things where you can have an animal that has a high breeding value but performs poorly, and that appears to be a contradiction and that undermines your confidence" (RU3).

When discussing the compatibility of DNA markers, respondents thought that DNA markers were compatible because the process of collecting the samples and receiving that data was straight forward and easy to implement into the enterprise. As an extension officer suggested,

"The implementation, if you are using it as a selection tool, is not hard. You see the two, three, or four stars for what you're chasing and how it's presented, and boom! Looks good." (E4).

Further, as the result is true throughout the animal's life, it is easy for producers to understand and incorporate into their existing knowledge. However, there was some comment that the results of the DNA marker tests were not representative of the overall performance of an animal and therefore are not reliable. 
"The gene marker will describe whether an animal has got a copy of a gene which might be one of many that affect a trait. So the thing would be not to, for beef producers to understand how much relevance they should place on things like individual gene marker tests" (E1).

In contrast, MSA was found to be highly compatible for beef producers. Implementation of MSA was seen as being best practice and producers could easily fit the new system in to the workings of the enterprise.

"I don't think it's all that complicated at all (to implement MSA into current practices). There are some basic things that farmers can do "on property" that would ensure the animals are well fed and you're going to kill without any dark cutters. There are some pretty clear guidelines I think with MSA, for farmers "(E5).

Each of the technologies evaluated appear to be problematic in at least one criteria. However all the technologies could provide some relative advantage to the end user.

\section{Discussion}

Findings from this study indicate that the 'innovation fit' characteristics can be assessed utilizing qualitative data, and such a review provides insights into potential adoption issues for an innovation. However, the results of this study also provide an explanation of why key some technological innovations are not always easily disseminated to and adopted by end-users. This may be due to Slater and Mohr's (2006) argument regarding the evolutionary nature of technological innovations which is products created from new scientific knowledge, evolve and improve overtime. Once the performance of the products improves and the 'innovation fit' is closer to the end-user's requirements, so that products experience higher levels of adoption. Of the key technologies identified in this study, only one(MSA) appears to have a good 'innovation fit' but it, too, could be improved. BREEDPLAN and DNA markers have high levels of complexity and score poorly on trialability and observability. Although all the technological innovations in this study were argued to have a high relative advantage compared to pre-existing technologies, this is not sufficient to ensure they are readily adopted by end-users. The cost of adopting a technology could outweigh the advantages and in cost sensitive industries such as agriculture, this may impact acceptance and the adoption of technologies. The inability to trial an innovation could lead to its failure to meet the expectations of the user (Yu \& Tao, 2008); the findings of this study demonstrate that trialing is not always possible and that can impact technology uptake. If technologies are to have a high adoption rate, it appears that, as Rogers and Shoemaker (1971) argued, they need to be trialable on a smaller scale and the results of trials need to provide evidence to the end-user that the technology works in practice. Also, technologies that are highly compatible with existing practices and do not cause major disruptions to processes and practices on farm may have a higher rate of adoption than disruptive technologies.

'Innovation fit' could play an important role in the initiation stage of the innovation adoption process. The findings in this research provide support for the work of Schmidt et al. (2009) who argue, review points are crucial for effective new product development. The review process could take place using researchers in an R\&D organization however this study demonstrates the benefits of involving experts from a range of organisations with different expertise in evaluating innovations. However, it is too late to involve experts and end-users after most of the development has been done. Conclusion

By reviewing the innovation fit of a technology, barriers to adoption were identified based on the study findings. However, if this is done early in the R\&D process, these barriers can be addressed by the researchers or others seeking to commercialise the technologies. This may help researchers to enhance the adoption rates of technologies. However, if the barriers are too great to be addressed economically, researchers could terminate the development of technologies due to poor innovation fit, hence enabling resources to be invested in other more appropriate technologies. This research has shown that using multiple criteria to evaluate technologies could be used to identify barriers to adoption. While this study is limited to a small number of technological innovations in beef production in Australia, the lessons learned here could be applied to other innovations. This study has demonstrated how 'innovation fit' could play an important role in the R\&D and innovation adoption process

\section{Acknowledgement}

This research was funded by the Beef CRC for Genetic Technologies

\section{References}

ABARE. (2006). Agricultural economies of Australia and New Zealand. Past, present and future. ABARE, Canberra. 
Bouwman, H., Van den Hoof, B., Van de Wijngaert, L., \& Van Dijk, J. (2005). Information and communication technology in organizations. Adaption, implementation, use and effects. London: Sage Publications.

Damanpour, F., \& Wischnevsky, J. D. (2006). Research on innovation in organizations: Distinguishing innovation-generating from innovation-adopting organizations. Journal of Engineering and Technology Management, 23, 269-291.

Department of Education Science and Training. (2005). Education and science: Working with industry. Canberra: Author.

Devine, M. D., James, T. E., \& Adams, T. I. (1987). Government supported industry-University research centers: Issues for successful technology transfer. Journal of Technology Transfer, 12(1), 27-37.

Gopalakrishnan, S., \& Damanpour, F. (1997). A review of innovation research in Economics, Sociology, and Technology management. Omega, 25(1), 15-28.

Graser, H-U., Tier, B., Johnston, D. J., \& Barwick, S. A. (2005). Genetic evaluation for the beef industry in Australia. Australian Journal of Experimental Agriculture, 45, 913-921.

Gregor, S., \& Jones, K. (1999). Beef producers online: Diffusion theory tpplied. Information Technology and People, 12(1), 71-85.

Guba, E. G., \& Lincoln, Y. S. (2005). Paradigmatic controversies, contradictions, and emerging confluences. In N. Denzin \& Y. S. Lincoln (Eds.) The sage handbook of qualitative research. (3rd ed.) (pp. 191 - 216). Thousand Oaks, CA: Sage Publications.

Guerin, L. J., \& Guerin, T. F. (1994). Constraints to the adoption of innovations in agricultural research and environmental management: A review. Australian Journal of Experimental Agriculture, 34, 549-71.

Hausman, A. (2005). Innovativeness among small businesses: Theory and propositions for future research. Industrial Marketing Management, 34, 773-82.

Hocquette, J.-F., Lehnert, S., Barendse, W., Cassar-Malek, I., \& Picard, B. (2007). Recent advances in cattle functional genomics and their application to beef quality. Animal, 1, 159-173.

Klein, K., \& Sorra, J. (1996). The challenge of innovation implementation. Academy of Management Review, 21(4), 1055-1080.

Klerkx, L., \& Leeuwis, C. (2007). Balancing multiple interests: Embedding innovation intermediation in the agricultural knowledge infrastructure. Technovation, 28, 364-378.

Lee, T. W. (1999). Using qualitative methods in organizational research. Thousand Oaks, CA: Sage Publications.

Massa, S., \& Testa, S. (2008). Innovation and SMEs: Misaligned perspectives and goals among entrepreneurs, academics and policy makers. Technovation, 28(7), 393-407.

Meat and Livestock Australia. (2008). MSA statistics. Sydney: Meat and livestock Australia [Online] Available: http://www.mla.com.au/TopicHierarchy/IndustryPrograms/MeatStandardsAustralia/MSA+statistics.htm (14 July, 2008)

Mullen, J., \& Crean, J. (2006). Strong agricultural productivity growth despite weaker public R\&D investment: Does this make sense? Farm Policy Journal, 3, 17-29.

Pannell, D. J., Marshall, G. R., Barr, N., Curtis, A., Vanclay, F., \& Wilkinson, R. (2006). Understanding and promoting adoption of conservation practices by rural landholders. Australian Journal of Experimental Agriculture, 46, 1407-1424.

Patton, M. Q. (2002). Qualitative research and evaluation methods. (3rd ed.). Thousand Oaks, CA: Sage Publications.

Rogers, E. M. (1962). Diffusion of innovations. New York: The Free Press.

Rogers, E. M. (1983). Diffusion of innovations. (3rd ed.). New York: The Free Press.

Rogers, E. M. (2003). Diffusion of innovations. (5th ed.). New York: The Free Press.

Rogers, E. M., \& Shoemaker, F. F. (1971). Communications of innovations. (2nd ed.). New York: The Free Press.

Schmidt, J.B., Sarangee, K., \& Montoya M.M. (2009). Exploring new product development project review practices. Journal of Product Innovation Management, 26(5), 520-535. 
Slater, S. F., \& Mohr, J. (2006). Successful development and commercialization of technological innovation: Insights based on strategy type. Journal of Product Innovation Management, 23(1), 26-33.

Taylor, J., \& McAdam, R. (2004). Innovation adoption and implementation in organizations: A review and critique. Journal of General Management, 30(1), 17-38.

Thompson, J. (2002). Managing meat tenderness. Meat Science, 62, 295-308.

Tornatzky, L. G., \& Klein, K. J. (1982). Innovation characteristics and innovation adoption-implementation: A meta-analysis of findings. IEEE Transactions on Engineering Management, EM-29(1), 28-43.

Van den Ban, A.W., \& Hawkins, H.S. (1996). Agricultural extension. (2nd ed.). Oxford: Blackwell Science Ltd.

Whan, I., Bortolussi, G., \& Backus, R. (2006). The impact of innovation on beef production in far northern Australia. Australian Journal of Experimental Agriculture, 46, 271-282.

Wolfe, R. A. (1994). Organizational innovation: Review, critique and suggested research directions. Journal of Management Studies, 31(3), 405-431.

Yu, C., \& Tao, Y. (2008). Understanding business-level innovation technology adoption. Technovation, 29(2), $92-109$.

Table 1. Technological innovation evaluation matrix.

\begin{tabular}{|l|l|l|l|l|l|}
\hline Innovation & Total & Frequency & Availability & Optional & Technological \\
\hline BREEDPLAN & 19 & $\checkmark(76 \%)$ & $\checkmark$ & $\checkmark$ & $\checkmark$ \\
\hline DNA Markers & 16 & $\checkmark(64 \%)$ & $\checkmark$ & $\checkmark$ & $\checkmark$ \\
\hline MSA & 13 & $\checkmark(52 \%)$ & $\checkmark$ & $\checkmark$ & $\checkmark$ \\
\hline Marker Assisted EBVs & 9 & $\checkmark(36 \%)$ & $\times$ & $\checkmark$ & $\checkmark$ \\
\hline NLIS & 7 & $\times(28 \%)$ & $\checkmark$ & $\times$ & $x$ \\
\hline Management Strategies & 7 & $\checkmark 28 \%)$ & $\checkmark$ & $\checkmark$ & $x$ \\
\hline Information technology & 4 & $\times(16 \%)$ & $\checkmark$ & $\checkmark$ & $\checkmark$ \\
\hline Feedlotting & 4 & $\times(16 \%)$ & $\checkmark$ & $\checkmark$ & $x$ \\
\hline Sustainability Practices & 2 & $\times(8 \%)$ & $\checkmark$ & $\checkmark$ & $x$ \\
\hline Composites and cross breeding & 2 & $\times(8 \%)$ & $\checkmark$ & $\checkmark$ & $\times$ \\
\hline Advanced reproduction\# & 2 & $\times(8 \%)$ & $\checkmark$ & $\checkmark$ & $\checkmark$ \\
\hline Growth Paths & 1 & $\times(4 \%)$ & $\checkmark$ & $\checkmark$ & $x$ \\
\hline Marketing & 1 & $\times(4 \%)$ & $\checkmark$ & $\checkmark$ & $x$ \\
\hline
\end{tabular}


Table 2. Analysis of the general innovation characteristics of the three key technical innovations

\begin{tabular}{|l|l|l|l|l|l|l|}
\hline & $\begin{array}{l}\text { Relative } \\
\text { advantage }\end{array}$ & Complexity & Trialability & Observability & Compatibility & Innovation Fit \\
\hline BREEDPLAN & $\begin{array}{l}\text { Yes } \\
\text { (positive) }\end{array}$ & $\begin{array}{l}\text { Yes } \\
\text { (negative) }\end{array}$ & $\begin{array}{l}\text { No } \\
\text { (negative) }\end{array}$ & $\begin{array}{l}\text { No } \\
\text { (negative) }\end{array}$ & Unclear & Low \\
\hline DNA Markers & $\begin{array}{l}\text { Yes } \\
\text { (positive) }\end{array}$ & $\begin{array}{l}\text { Yes } \\
\text { (negative) }\end{array}$ & $\begin{array}{l}\text { No } \\
\text { (negative) }\end{array}$ & $\begin{array}{l}\text { No } \\
\text { (negative) }\end{array}$ & $\begin{array}{l}\text { Yes } \\
\text { (Positive) }\end{array}$ & Low \\
\hline MSA & $\begin{array}{l}\text { Yes } \\
\text { (positive) }\end{array}$ & $\begin{array}{l}\text { No } \\
\text { (positive) }\end{array}$ & Unclear & Unclear & $\begin{array}{l}\text { Yes } \\
\text { (positive) }\end{array}$ & moderate \\
\hline
\end{tabular}

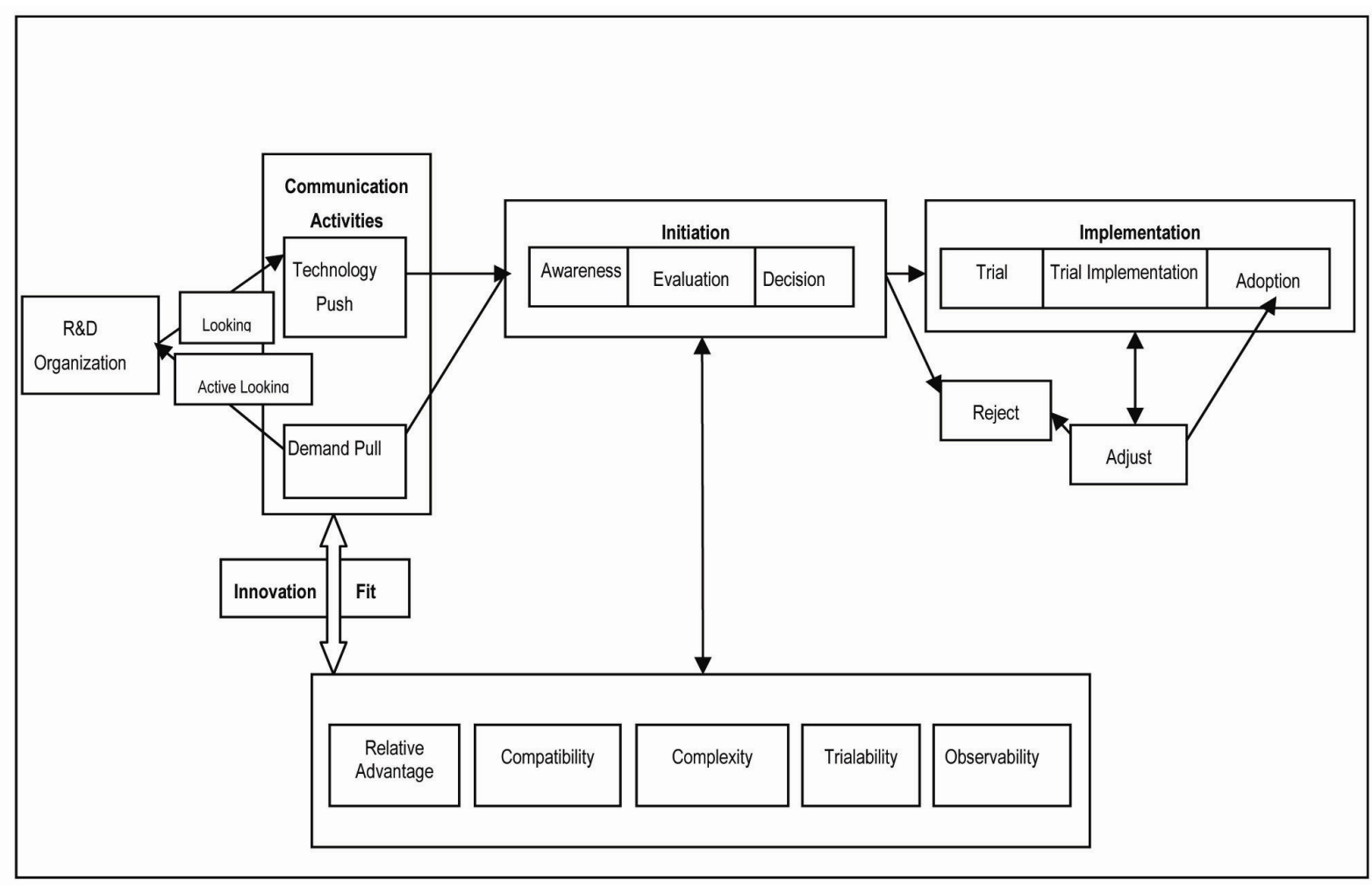

Figure 1. Innovation fit in the adoption process 